\title{
Unexpected Difficult Intubation in a Patient with Prominent Mandibular Tori
}

\author{
Jaydev Sarma*
}

\author{
Harvard Medical School, Staff Anesthesiologist, Department of Anesthesia, Critical Care and Pain Medicine, \\ Massachusetts General Hospital, Boston, MA, 02114, USA
}

\begin{abstract}
Bony exostoses such as mandibular tori are fairly common. They are asymptomatic, benign cortical bony protuberances occurring along the lingular aspect of the mandible. Large tori may interfere with direct laryngoscopy resulting in difficult intubation. This is a case report about a 66 year old, Caucasian male with a Mallampati class I airway who was un-intubatable initially, due to the presence of bilateral mandibular tori that formed a plate of bone beneath his tongue. He was intubated subsequently with the help of an Eschmann bougie.
\end{abstract}

Keywords: Difficult intubation, mandibular tori, palatal tori, torus mandibularis, torus palatinus.

\section{INTRODUCTION}

A pre-operative airway examination usually focuses on certain superficial aspects such as the morphology of the head, size of the neck, neck mobility, size of the mandible, thyro-mental distance, dental status and intra oral views of the tongue and pharyngeal soft tissue structures using guides such as the Mallampati classification [1].

There are few case reports mentioning mandibular tori as a cause of difficult intubation [1-3]. This case is presented to emphasize the importance of including an evaluation of the floor of the mouth in all pre-operative airway examinations.

\section{CASE REPORT}

The patient was a 66 year old Caucasian male scheduled for a washout of a chronically infected hip and vacuum dressing change. His past medical history included hypertension, hyperlipidemia, diverticulitis, benign prostatic hypertrophy, ankylosing spondylitis and osteoarthritis of his hips for which he underwent bilateral hip replacements. The patient then developed wound infection and osteomyelitis of the left hip, requiring incision and drainage, explantation of the hardware and debridement. He had been managed by both orthopedics and infectious diseases departments, and had been scheduled for a wound washout and replacement of the tobramycin spacer in the left hip. He was taking metoprolol, fluoxetine, oxycodone, tamsulosin, nafcillin, and ciprofloxacin. He was $160 \mathrm{~cm}$ tall and weighed $48 \mathrm{~kg}$ (BMI=18.6). He had a long neck, a thyromental distance of at least four fingerbreadths, good cervical spine mobiltiy with a full range of motion. He had a small mouth with crowded teeth, and the airway was a Mallampati I view. The

\footnotetext{
*Address correspondence to this author at the Harvard Medical School, Staff Anesthesiologist, Department of Anesthesia, Critical Care and Pain Medicine, Massachusetts General Hospital, Boston, MA, 02114, USA; Tel: 617724 7182; Cell: 508463 7918; Fax: 617643 4040;

E-mail: jsarma@partners.org
}

patient also had bilateral mandibular tori which met at the midline of the floor of mouth. His hematocrit was 33.6\%, blood urea nitrogen level of $11 \mathrm{mg} / \mathrm{dl}$ and creatinine of $1.7 \mathrm{mg} / \mathrm{dl}$ for an estimated glomerular filtration rate of $40 \mathrm{ml} / \mathrm{min}$. The patient had a peripherally inserted central catheter (PICC) line for intravenous access. He had tolerated previous general anesthetics with a laryngeal mask airway (LMA) but we decided to secure the airway with an endotracheal tube as the surgeon wanted the patient to be positioned on his right lateral side.

The patient was pre-medicated with $2 \mathrm{mg}$ of midazolam and $100 \mathrm{mcg}$ of fentanyl. He was induced with $120 \mathrm{mg}$ of propofol and $8 \mathrm{mg}$ of cis-atracurium after ascertaining adequate mask ventilation. Intubation was initially attempted

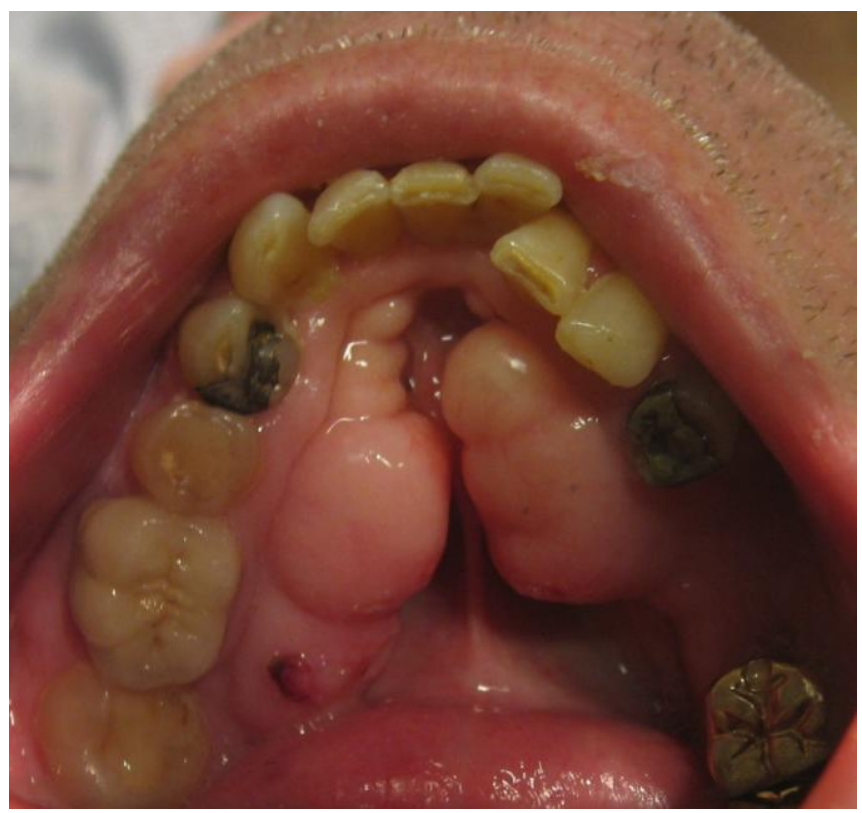

Fig. (1). Superior view of the madibular tori. 


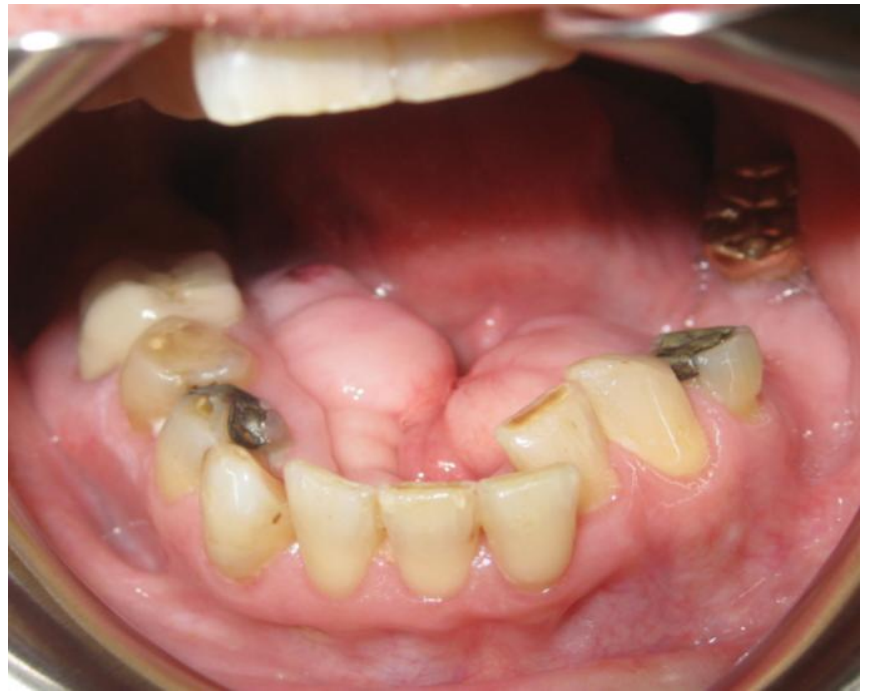

Fig. (2). Frontal view. Mandibular tori occluding the floor of the mouth.

by the resident with a MacIntosh, size 3 laryngoscope and he was unsuccessful despite using cricoid pressure. The mandibular tori significantly limited the ability to depress the floor of mouth inferiorly and anteriorly. A subsequent direct laryngoscopy by the staff anesthesiologist, revealed only the tip of the epiglottis with a grade III Cormack and Lehane view of the larynx [2]. An Eschmann bougie was passed blindly beneath the epiglottis and a $7.0 \mathrm{~mm}$ endotracheal tube was successfully rail-roaded over it into the trachea. The position of the endotracheal tube was confirmed by the presence of end-tidal carbondioxide and bilateral breath sounds on auscultation. The remainder of the operation was uneventful and the patient was extubated after reversing the neuromuscular blockade with neostigmine and glycopyrrolate.

There were no post-operative complications and the anesthesiologist had a thorough discussion with the patient regarding the difficult intubation. Excision of the tori was recommended to prevent anesthetic complications in the future. A detailed difficult intubation letter was given to the patient and the note was posted in his electronic medical records.

\section{DISCUSSION}

A number of factors could have contributed to the difficult intubation in this patient. He had a small mouth with crowded teeth, an anteriorly placed larynx, as well as large mandibular tori, which formed a unyielding plate of bone underneath the tongue. These tori prevented the normal displacement of the tongue and the floor of the mouth resulting in a poor laryngoscopic view.

Difficult intubation may be expected when there is a limitation of mouth opening, poor dental status, a class IV Mallampati view [1], shortened thyromental distance, and a severe limitation of cervical spine mobility.

Other factors may include pathology along the airway, or certain benign conditions that may alter the airway. Among the latter are mandibular and palatal tori. Their prevalence is well described in dental and oral surgery literature, but is seldom mentioned as a problem during general anesthesia [3-5].

Mandibular and palatal tori are bony exostoses present on the lingual aspect of the mandible or in the midline of the palate. Exostoses are localized bony protuberances arising from the cortical plate [6]. Intra oral exostoses are among the most common. The mandibular torus typically occurs above the myelohyoid line of the mandible, in the region of the premolars [7]. When present, tori occur bilaterally in up to 90\% of cases [6]. African Americans and Asians having a higher prevalence $[6,8]$ with the highest being reported in the Alaskan Eskimo and Eastern Aleut populations at $61 \%$ $[9,10]$. It is thought that the development of tori is multifactorial, with both genetic and environmental factors [11]. It is suggested that they develop in response to stress and bruxism, and can enlarge with age [1, 5, 9].

Mandibular tori are benign growths and do not cause a problem in daily activities. Histopathology of removed tori reveals dense cortical and lamellar bone $[6,8]$.

Treatment of mandibular and palatal tori is only necessary if they cause a problem for the patient. Removal is warranted if the thin overlying mucosa has been traumatized or causes pain. In some cases food entrapment leading to deterioration of oral hygiene may occur. Providers unfamiliar with this abnormality may mistake it for malignancy and order unnecessary tests and investigations.

Anesthesiologists should be aware of these structures and the challenges they pose. Routine intubation in the presence of large tori may limit the laryngoscopic view by hindering the downward movement of the infra glottic soft tissue.

Large palatal tori may interfere with intubation and laryngeal mask airway placement. The mucosa covering these growths is fragile and prone to trauma and hemorrhage during laryngoscopy, intubation, extubation and other intraoral manipulations.

\section{CONFLICT OF INTEREST}

The author has no conflict of interest to declare in relation to the content of this article.

\section{ACKNOWLEDGEMENTS}

The author would like to acknowledge the patient's cooperation for permitting photography and allowing this case presentation.

\section{REFERENCES}

[1] Mallampati SR, Gatt SP, Gugino LD, et al. A clinical sign to predict difficult tracheal intubation: a prospective study. Can Anaesth Soc J 1985; 32(4): 429-34.

[2] Cormack RS, Lehane J. Difficult tracheal intubation in obstetrics. Anaesthesia 1984; 39: 1105-11.

[3] Takasugi Y, Shiba M, Okamoto S, Hatta K, Koga Y. Difficult laryngoscopy caused by massive mandibular tori. J Anesth 2009; 23: $278-80$.

[4] Durrani MA, Barwise JA. Difficult endotracheal intubation associated with torus mandibularis. Anesth Analg 2000; 90: 757-9. Woods GM. Mandibular tori as a cause of inability to visualize the larynx. Anesth Analg 1995; 81: 870-1.

[6] Gonsalves WC, Chi AC, Neville BW. Common oral lesions. Part 11. Masses and neoplasia. In: Neville BW, Damm DD, Allen CM, 
Bouquot JE, Eds. Oral and maxillofacial pathology. Philadelphia: WB Saunders 2002: 18-22.

[7] Choi Y, Park H, Lee JS, et al. Prevalence and anatomic topography of mandibular tori: computed tomographic analysis. J Oral Maxillofac Surg 2012; 70(6): 1286-91.

[8] Sonnier KE, Horning GM, Cohen ME. Palatal tubercles, palatal tori, and mandibular tori: prevalence and anatomical features in a U.S. population. J Periodontol 1999; 70: 329-36.
[9] Hrdlicka A. Mandibular and maxillary hyperostoses. Am J Phys Anthropol 1940; 27: 1-67.

[10] Moorrees CF. Dentition as a criterion of race with special reference to the Aleut. J Dent Res 1951; 30(6): 815-21.

[11] Demetrios ZA, Maria B, Panayiotis P. Concurrence of torus palatinus with palatal and buccal exostoses. Oral Surg Oral Med Oral Pathol Radiol Endod 1998; 85: 552-7.

(C) Jaydev Sarma; Licensee Bentham Open.

This is an open access article licensed under the terms of the Creative Commons Attribution Non-Commercial License (http://creativecommons.org/licenses/by-nc/3.0/) which permits unrestricted, non-commercial use, distribution and reproduction in any medium, provided the work is properly cited. 